\title{
What Does the Energy Industry Require from Meteorology?
}

\author{
Laurent Dubus, Shylesh Muralidharan, \\ and Alberto Troccoli
}

\begin{abstract}
The energy sector significantly depends on weather and climate variability, which impacts both demand and supply, at all timescales. Over the next decades, climate change mitigation and adaptation will lead to an overhaul in energy systems, to reduce greenhouse gases emissions. Low carbon energy generation is key to facing this challenge, but its renewable part-mainly from wind, solar and hydro power-will even increase the exposure of the sector to weather and climate factors. Energy companies can assess their preparation to tackle the impact of weather volatility on their operations by running a weather-readiness assessment. This chapter provides an overview of the energy sector today, together with future scenarios and challenges. The weather-readiness concept is then presented in detail and demonstrates that stronger collaboration between the energy
\end{abstract}

L. Dubus $(\triangle)$

EDF - R\&D, Applied Meteorology group, Chatou, France

S. Muralidharan

Schneider Electric, Burnsville, MN, USA

A. Troccoli

World Energy \& Meteorology Council, c/o University of East Anglia, Norwich, UK

(C) The Author(s) 2018

A. Troccoli (ed.), Weather \& Climate Services for the Energy Industry, https://doi.org/10.1007/978-3-319-68418-5_4 
industry and the meteorological community is key to reducing the risks posed by climate variability and change, and allow a more effective integration of high-quality weather and climate information into energy sector activities, to better manage power systems on all timescales from a few days to several decades.

Keywords Energy systems • Energy scenarios • Supply • Demand • Weather readiness

\section{INTRODUCTION}

The energy sector is weather and climate dependant. Both day-to-day weather and longer-term climate variability have impacts on supply, demand, transport and distribution, and energy markets. Despite the energy sector being one of the most advanced users of weather and climate information, its rapid evolution constantly creates new needs, which require a new paradigm for a more effective exchange of information between meteorologists and energy sector users. Scientific progress on its own is indeed not sufficient to increase the value of weather forecasts. Indeed, improving decision-making processes, and hence the value of meteorology, also demands improved communication and mutual understanding between energy and meteorology people.

In the last decade, a burgeoning number of sessions in Energy \& Meteorology at various conferences (e.g. American Meteorology Society, European Meteorology Society, European Wind Energy Conference) started the process from the meteorology side, aiming to engage the energy side. The International Conference on Energy \& Meteorology (ICEM) series is going one step beyond to support a bidirectional stream of communication. The third ICEM in Boulder in 2015 provided a platform for a seminar on Energy for Meteorologists, with three main objectives:

1. To provide meteorologists with an overview of the energy sector/ business

2. To enhance awareness of the importance of weather and climate for the energy sector

3. To help foster a dialog between both communities and to identify major challenges which should be addressed in a co-design approach in the coming years 
This chapter summarizes the content of the seminar and suggests ways to improve and develop collaboration between weather and climate scientists on the one side, and energy practitioners on the other.

\section{Overview of the Energy Sector/Business}

Energy systems are the engine of economic and social development. As stated in the SE4ALL' 2014 report (SE4ALL 2014): 'Energy is the golden thread that connects economic growth, increased social equity and an environment that allows the world to thrive. Energy enables and empowers. Touching on so many aspects of life, from job creation to economic development, from security concerns to the empowerment of women, energy lies at the heart of all countries' core interests.' On the other hand, the energy sector is responsible for the largest share of anthropogenic greenhouse gas emissions. Reducing this footprint on global climate demands increasing the share of low carbon technologies, as well as increasing energy efficiency, while the global energy demand will continue to rise. Before going into further detailed implications of these basic elements, we first present here a quick overview of the energy sector, with a special focus on the power sector.

As things are moving very fast in the world energy landscape, the reader should note that the figures given here are a snapshot taken at the time of writing. There are a lot of resources when one wants to look in detail at the state of world energy systems. The most relevant ones are listed at the end of this chapter. The World Energy Council (WEC), ${ }^{2}$ the International Energy Agency (IEA) ${ }^{3}$ and REN2 $1^{4}$ annual publications are among the most relevant to keep updated on the status of the energy sector.

\section{Peculiarities of Energy Systems}

Energy systems exhibit some common features, like other public good service sectors such as water and transport infrastructure for instance. First, they are capital intensive, with huge investments needed when one considers grid development or construction and operation of large production units. They are also characterized by long life cycles, on the lower order of 20 years for wind or solar farms, for instance, to as much as, or even more than, 60-80 years for heavy infrastructures, like large power plants, hydropower dams and transport networks. Last, but not least, energy markets are fragmented geographically, most generally at national level, and are sometimes subject to security issues. 
Energy systems consist of a great diversity of generation sources, with very different characteristics in terms of:

- Technical aspects: size, net generation capacity, efficiency, reliability, operating constraints...

- Economic aspects: fixed and variable (operating) costs can vary a lot from one production means to another

- Regulatory aspects: $\mathrm{CO}_{2}$ or other gas emissions limits, security rules, health and environmental impact regulations.

Energy systems are not isolated, but fully integrated in human activities, and closely linked to other sectors, in particular water. Water is indeed necessary for energy generation, either as the cooling fluid for some thermal power generation units or as the engine for hydropower generation. In addition, pumping, treating and moving water requires electricity. There are then strong links and dependencies between the energy and the water sectors, and, consequently, also with the food sector. This interlinkage is referred to as the energy-water-food nexus. It reflects the fact that there are competing uses of a common resource (water) for different human activities. Competition between energy generation, water supply and crop irrigation is already an issue in water scarce areas. It will become even more problematic in the next decades, with increased tensions on water resources due to climate change impacts (WEC 2016a).

As this chapter focuses on the power sector, we must add here some specificities of electricity as a commodity:

- Real-time balance between generation and consumption: as storage capacity is limited and/or very expensive, electricity cannot be currently stored on a large scale. Real-time balance between consumption and production must then be ensured in real time;

- Electricity demand is very variable in time, with characteristics varying among countries, depending on the uses of electricity for heating, cooling or any other application;

- Prices are very volatile: the electricity sector is now liberalized in most countries, and prices can fluctuate strongly according to trading opportunities on the markets;

- Natural monopolies: despite liberalization, network topologies impose physical constraints even on interconnected networks, as only limited amounts of energy can flow from one country to its neighbours; 
- Technical complexity: there are difficulties in controlling load flows, interactions between generation and transmission (network congestion, blackout risks) and very diverse plant characteristics;

- Economic model: economic dispatch of production is based on increasing variable costs, the cheapest generation unit being called first. This implies that the marginal production cost of electricity increases with volume, contrary to most other commodities, and that a $\mathrm{kWh}$ is more expensive during a peak in load. However, in some markets, wind and solar energy are preferred, in line with $\mathrm{CO}_{2}$ emissions reduction targets, and must be the first supply source in the stack, requiring more flexibility from other sources to account for their variability in time.

\section{The Current Global Energy Picture}

The IEA annual Key World Energy Statistics provides a regular overview on past trends, the current picture, and projections to 25 years ahead for energy production and consumption, as well as $\mathrm{CO}_{2}$ emissions and energy prices. The 2016 edition (IEA 2016a) confirms past trends: globally, total primary energy supply and final consumption have constantly increased since 1973. Table 4.1 presents the main figures.

In $2014,{ }^{5}$ the share of energy sources in the global final energy consumption was roughly subdivided as shown in Fig. 4.1 (REN21, 2016).

Table 4.1 Main trends in energy supply and consumption and electricity generation from 1973 to 2014

\begin{tabular}{|c|c|c|c|}
\hline & 1973 & 2014 & Comments \\
\hline $\begin{array}{l}\text { Total primary energy } \\
\text { supply }\end{array}$ & $\begin{array}{l}\text { 6101 Mtoe } \\
(70,955 \text { TWh })\end{array}$ & $\begin{array}{l}\text { 13,699 Mtoe } \\
(159,319 \text { TWh })\end{array}$ & $\begin{array}{l}\text { Relative decrease in oil, } \\
\text { increase in coal and } \\
\text { natural gas }\end{array}$ \\
\hline $\begin{array}{l}\text { Total final energy } \\
\text { consumption }\end{array}$ & $\begin{array}{l}4661 \text { Mtoe } \\
(54,207 \text { TWh })\end{array}$ & $\begin{array}{l}9425 \text { Mtoe } \\
(109,613 \text { TWh })\end{array}$ & $\begin{array}{l}\text { - Largest increase in } \\
\text { China/Asia } \\
\text { - Decrease in oil, increase } \\
\text { in electricity }\end{array}$ \\
\hline Electricity generation & $6131 \mathrm{TWh}$ & 23,816 TWh & $\begin{array}{l}\text { Increase in nuclear, } \\
\text { natural gas, renewables, } \\
\text { - Decrease in oil }\end{array}$ \\
\hline
\end{tabular}

Source: IEA (2016a)

${ }^{\mathrm{a}} 1 \mathrm{Mtoe}=1.163 \times 10^{4} \mathrm{GWh}$ 


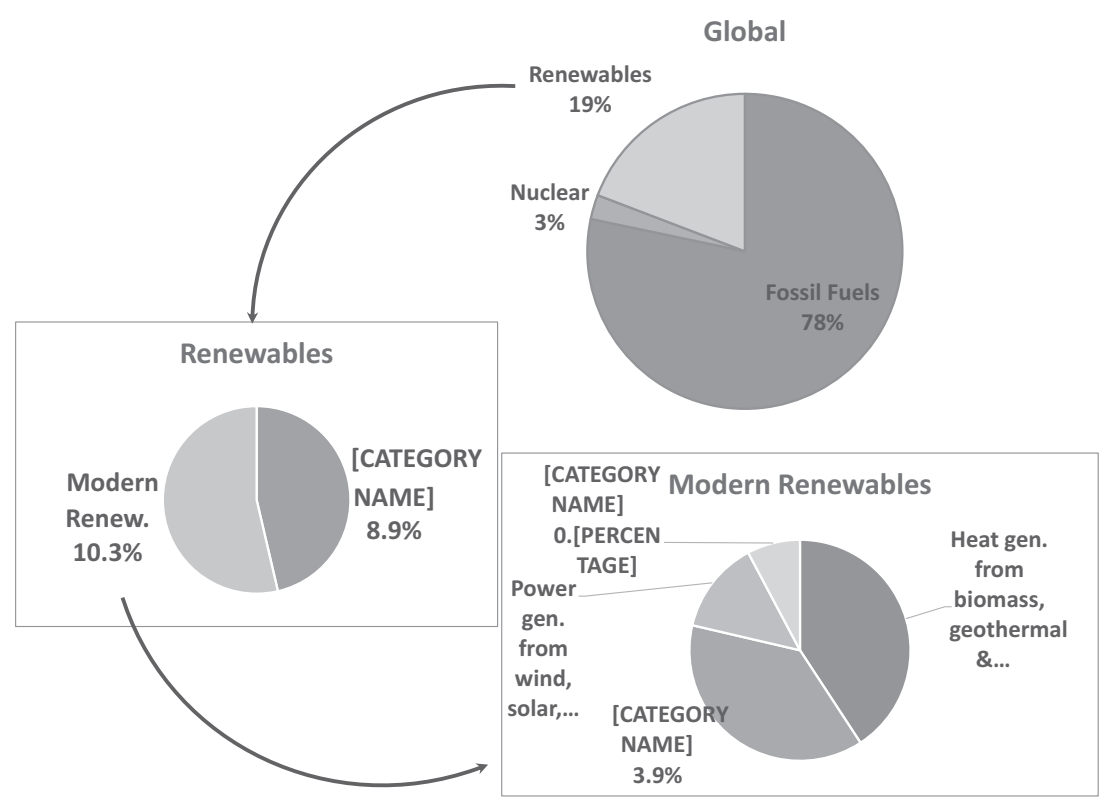

Fig. 4.1 Share of energy sources in the global final energy consumption (adapted from REN21 2016)

Obviously, fossil fuels still dominate at global scale. But this picture masks strong disparities between countries. For instance, whereas renewable sources represent only $8 \%$ of the final energy consumption in Belgium, this increases to $69.2 \%$ in Norway, mainly due to hydropower (WEC 2016b).

Focusing on power generation, wind and solar energy have been rapidly developing in the last decade, with an average annual growth of the installed capacity of 23\% per year between 2004 and 2014 for wind and $51 \%$ per year for solar (WEC 2016c). This increase has been favoured by different factors, among which are incentives to develop these low-carbonemitting technologies and a strong decrease in costs, in particular for solar panels. Overall, investments in renewable energy sources increased from US $\$ 72.8$ billion in 2005 to US\$285.9 billion in 2015 , mainly dedicated to solar (US\$161 billion) and wind (US\$110 billion). As a result, the addition of new capacity in the power sector was higher in 2015 for renewables than for coal, gas, oil and nuclear combined (IEA 2016b). Overall, 
renewables, including hydropower, now account for about $30 \%$ of the total global installed power generation capacity and $23 \%$ of total global electricity production (WEC 2016c).

The effects of this energy transition towards cleaner technologies are becoming important also in terms of emissions. Indeed, $\mathrm{CO}_{2}$ emissions from fossil fuels, which were increasing until 2013, seem to have stalled in 2014 and decreased in 2015 despite continued economic growth (Jackson et al. 2015, see their Fig. 1). The main reasons for this change in trend are a decrease in coal use in China, slower global growth in oil and the previously mentioned faster growth in renewables. The latter, together with a transfer from coal and oil to natural gas energy production, has implied a reduction in carbon and energy intensity, in particular in the USA and the UK.

\section{Future Scenarios}

Many organizations produce future scenarios for the energy sector, generally no further than 50 years ahead due to too many uncertainties. At institution level, a few scenarios are generally considered that cover a range of technical, economic and political options. Those scenarios are driven by the need for more energy supply, in response to increase in demand, and by the indispensable adaptation of the energy sector to climate change. Obviously, energy access for those who do not have secure, affordable and sustainable access to energy, the three pillars of the WEC Energy Trilemma (WEC 2016d), is an essential target. This currently concerns 1.2 billion people in the world. Despite differences between these scenarios, common features emerge. We here reproduce the main points highlighted by WEC (WEC 2016e) and IEA (IEA 2016b).

1. Energy demand will keep increasing, but per capita demand may peak around 2030 due to increased energy efficiency from new technologies and more stringent energy policies.

2. Fossil (coal, oil) fuels' share will decrease overall. Oil demand growth will be due mainly to freight, aviation and petrochemicals. Decarbonizing the global transport system is challenging, as the total number of vehicles is expected to double by 2040 , and only few alternatives to fossil fuels exist. However, efficiency gains, use of biofuels and development of electric vehicles will make it possible to significantly reduce fuel demand for passenger vehicles. Among fossil fuels, natural gas will be more widely used. 
3. Electricity demand is likely to double by 2060 . This is driven first by the fact that the electricity sector will be easier to decarbonize than the others (transport in particular) and by an increase in urbanization and the associated development of technology-enabled lifestyles, which require more electricity.

4. Renewable sources, especially wind and solar energy, will be key in delivering low-carbon electricity. Today, they provide around $4 \%$ of power generation, but according to WEC's scenarios, their share could rise to between $20 \%$ and $39 \%$ by 2060 (WEC 2016e). Time and spatial variability of wind and solar generation poses risks to electricity security. Their integration will require a significant change in power system design and operation, allowing more flexibility to compensate for increases in variability from renewable generation. Several solutions therefore need to be developed in parallel to facilitate large wind and solar energy integration:

- demand response and management;

- increase in energy efficiency and conversion rates;

- stronger and smarter grids, including development of system services;

- availability of short-term backup power generation;

- energy storage, from water reservoirs, hydrogen, compressed air and batteries

The energy sector transition is now underway, and has been accelerated by the pledges made as part of the COP21 Paris Agreement in 2015. However, most energy scenarios show that the carbon budget for a $2{ }^{\circ} \mathrm{C}$ target could be reached as soon as 2040 (IEA's main scenario, IEA 2016b), or between 2040 and 2060 (WEC 2016e). Most analysts therefore agree that the $2^{\circ} \mathrm{C}$ pathway will require stronger efforts than the currently pledged commitments, while a $1.5^{\circ} \mathrm{C}$ target has not yet been addressed from the energy point of view. Addressing the energy sector challenges will require global cooperation, sustainable economic growth and technology innovation, together with political decisions and actions to fix a (high) carbon price.

\section{The Energy Trilemma}

The WEC's definition of energy sustainability is based on three core goals-energy security, energy equity and environmental sustainability. 
Balancing these three goals constitutes a 'trilemma' and is the basis for prosperity and competitiveness of individual countries. This trilemma neatly summarizes the energy sector's challenges. Since 2013, annual reports provide guidance to translate the three goals into tangible actions (WEC 2016d). More specifically, the three Energy Trilemma goals are defined as:

- Energy security: The effective management of primary energy supply from domestic and external sources, the reliability of energy infrastructure and the ability of energy providers to meet current and future demand;

- Energy equity: Accessibility and affordability of energy supply across the population;

- Environmental sustainability: Encompasses the achievement of supply and demand side energy efficiencies and the development of energy supply from renewable and other low-carbon sources.

The 2016 report (WEC 2016d) suggests five focus areas to achieve those goals, as shown in Fig. 4.2. Meteorology, that is weather observation, forecasts and longer-term climate projections, will play an increasing role in helping achieve these objectives. A more effective integration of weather and climate information into energy systems will also require

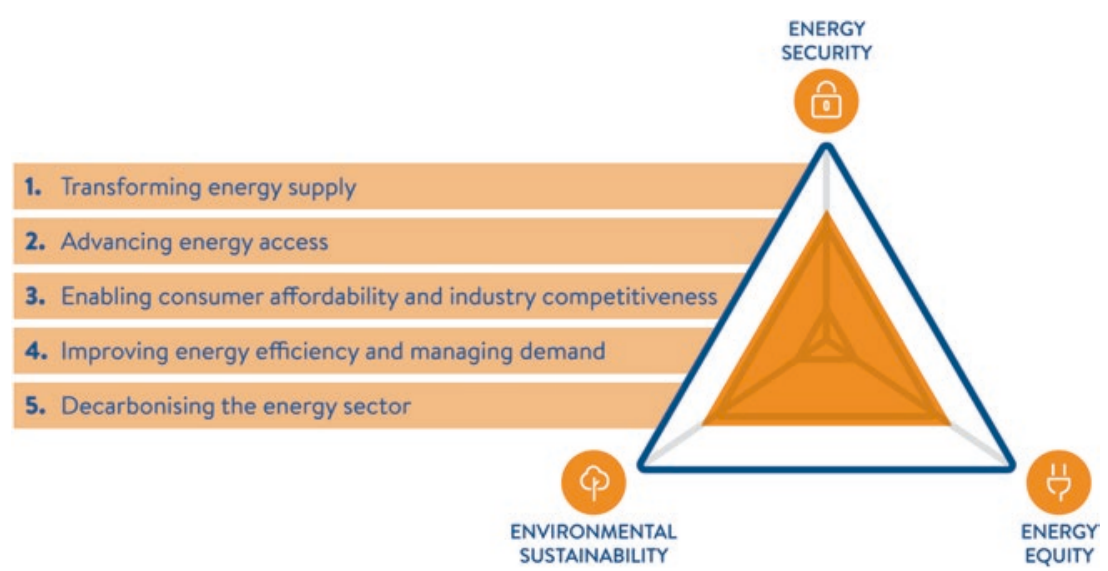

Fig. 4.2 The World Energy Council's Energy Trilemma, and the five focus areas for achieving energy goals (WEC 2016d). Used by permission of the World Energy Council 
fostering the collaboration between the meteorology community and the energy sector, from the utilities level up to the policymakers level (WEC 2016d).

\section{The Importance of Weather and Climate FOR THE ENERGy SECTOR}

\section{Weather and Climate Impact the Energy Sector on All Timescales}

Influences of short-term weather variability and longer-term climate impacts on the energy sector are well documented today. Among the available publications, most chapters, if not all, in Troccoli et al. (2014) give multiple examples and figures about these close links, which concern more or less all the fields of activity in the energy business, as exemplified in Fig. 4.3. In addition to the physical links between, for example, variable cloud cover and PV generation variability or between long droughts and reduced hydropower generation, weather and climate variability also have strong impacts on energy markets and energy system finance.

Variability of the weather-driven part of energy demand and supply causes energy prices to vary. The way energy prices vary depend also on

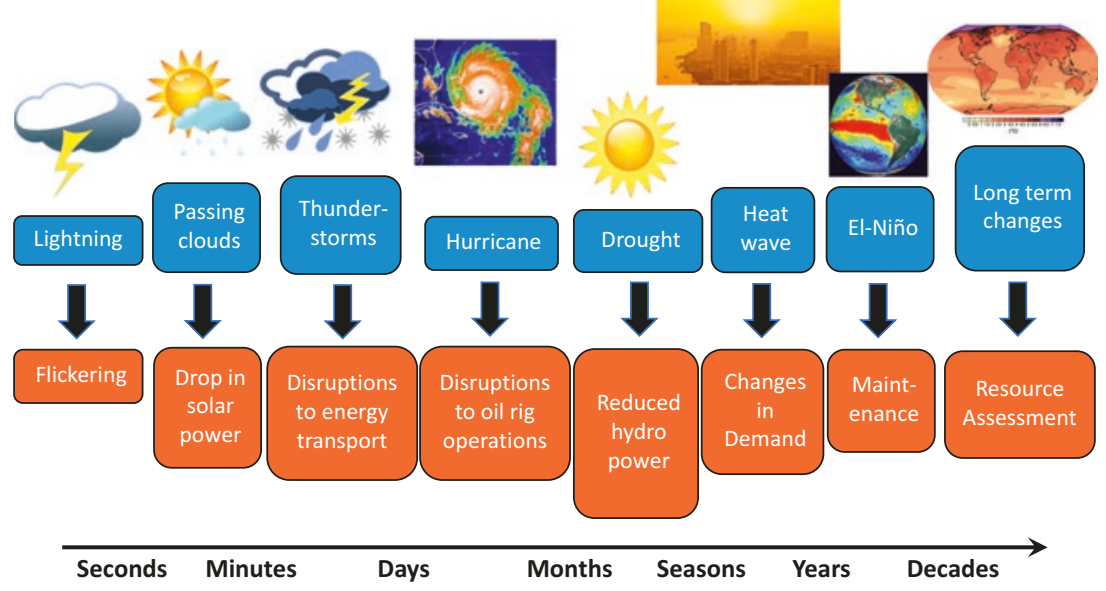

Fig. 4.3 Weather and climate impact the energy sector on all timescales (source: WEMC) 
the underlying trading schemes. Long-term contracts are managed on forward markets, where week-ahead, month-ahead, quarter-ahead and even (up to three) year-ahead products are most often traded in the form of bilateral contracts.

Energy volumes can be purchased or sold on intra-day and day-ahead spot markets, similar to stock exchanges. In addition, in countries where energy load balancing is actively managed, Transmission System Operators (TSOs) and national regulators have set up balancing mechanisms to be able to mobilize extra generation or consumption reduction in case of higher than expected demand, and generation modulation or even curtailment in the case of lower than expected demand, the final goal being of course to ensure the supply-demand balance in real time. As electricity prices follow the offer/demand law, prices can increase significantly during peak demand. To fulfil low-emission energy development targets, renewable energy is prioritized in most countries to meet the demand. The increasing share of variable wind and solar generation then increases the volatility of net demand, defined as consumer demand minus renewable supply, and then that of prices. Any actor on the market who is able to forecast supply and demand better than competitors is then in a favourable position to buy and sell energy in a profitable way.

Energy system long-term financing is also more and more impacted by weather and climate, for two main reasons:

1. the increase in strongly weather-dependant wind and solar energy, and

2. the increasing vulnerability of energy assets to climate change.

Indeed, renewable energy projects' bankability (likelihood to ensure the financial success of the project), and hence financing through bank loans, depends on the projected resource and profit over the full investment and operation period, generally between 15 and 30 years. The resource estimation needs of course to be as accurate as possible, as any overestimation will result in less profit. Together with the technical choices about the production unit's characteristics, the resource estimation is a key factor in determining the Levelized Cost Of Energy (LCOE) of a project, this parameter often being the main or even the only determining selection criterion among competitive bids. As an example, EDF R\&D and HYGEOS (Elias et al. 2015, 2016; Garnero et al. 2016) are developing new methodologies to estimate the solar radiation attenuation by aerosols 
in the surface layer (between 0 and $200 \mathrm{~m} \mathrm{AGL}$ ) in solar thermal plants, on the slant path from the heliostats (mirrors) to the concentrating tower. For instance, in Ouarzazate, Morocco, slant path attenuation can vary between $0 \%$ and $20 \%$ during desert dust events, significantly impacting the estimated long-term resource. Improved horizontal attenuation measurement and long-term estimation can significantly modify the LCOE calculation. This requires improvements in attenuation measurements during field campaigns in rough terrains, and new methodological developments to extrapolate short in situ measurements on the longer term, by coupling with satellite data and/or reanalysis.

More recently, long-term investments have started to take into account also the potential future impacts of climate change. As scientific consensus on future climate change has now been reached (IPCC 2013), this dimension has become a key factor in energy system development and new power plant projects. This is particularly true for long-term assets such as big dams or nuclear power plants, as well as power networks.

The International Hydropower Association ${ }^{6}$ (IHA) status report 2016 (IHA 2016) notes that many countries are seeking a better understanding of climate change impacts and are beginning to build climate adaptation strategies and climate resilience into their plans. Many policymakers and industry leaders require guidelines and a robust framework for approaching climate risks. The World Bank is also very active in defining and developing guidelines for the hydropower sector (and more generally the whole energy sector), in order to help countries and businesses building resilience for both existing hydropower infrastructure and future projects. Its Energy Sector Management Assistance Program ${ }^{7}$ (ESMAP) in particular provides analytical and advisory services to low- and middle-income countries to increase their know-how and institutional capacity to achieve environmentally sustainable energy solutions for poverty reduction and economic growth. In addition, many funding agencies and development banks now require that any long-term project includes a comprehensive assessment of climate change impacts (see for instance HRW 2014).

Many energy companies already consider climate change in their investment plans. For instance, EDF takes climate change into account when assessing the possible changes of efficiency of its thermal and nuclear power plant cooling systems (Anderhalt 2015).

Generally, the energy sector is, today, well aware that weather and climate variability and change impact their business, at every timescale. But not all companies and policymakers do take this quantitatively into account 
in planning and operations. The next paragraph shows why weather readiness is important, and how this concept can help the sector deal with weather and climate risks.

\section{Weather Readiness Is Key for Weather-Resilient Business Performance for Electric Utilities}

\section{Weather-Readiness Assessment-Background and Introduction}

Recent research (Francis et al. 2014) shows that in the past couple of decades, changing climate trends have led to increasing volatility in weather patterns across the world. This has significantly impacted the daily business operations of entities across the electricity supply value chain. Electric power generation entities are stressed during extremely anomalous hot or cold weather events as extreme weather forces them to 'make or buy' energy worth millions of dollars. Energy becomes a scarce commodity during extreme events and good knowledge of weather forecasts helps companies to take decisions to produce or procure energy at the right time and at an economical cost and help them be ready for severe weather in the most efficient manner. For companies involved in activities down the value chain such as electricity transmission and distribution, weather definitely has had an increasing impact on operational reliability (IDC 2013) in recent decades. Every time there is a severe weather event, the delivery of electricity is impacted and customers may be without power for several hours or days depending on the strength of the storm and the ability of the utility to restore power in their service territory.

Outages have a significant economic impact as well. Severe weatherrelated outages cost the US economy a total of approximately $\$ 80$ billion annually (LaCommare and Eto 2006), half of which impacts the industrial and digital economy. Electric Power Research Institute (EPRI) research shows that the economic cost of power outages is largely related to the length of the outage, while noting even short duration outages of a few minutes could have large costs. It is estimated the average cost of a onehour outage for manufacturing and digital economy firms is $\$ 7795 /$ firm (Baggini 2008). Among industrialized countries, the USA has one of the highest annual average outage durations per customer, and also one of the highest annual average number of supply outages per customer; more than $45 \%$ of US utilities have a System Average Interruption Duration Index (SAIDI) metric of greater than 100 mins/year. The economic cost of 
these outages impacts not only end-users of utilities but also utilities themselves. More than $60 \%$ of utilities in the USA lose more than $\$ 100,000$ on average per year in revenues due to outages and this number does not even include the unplanned costs of response and restoration.

\section{Rationale for Investing in Weather-Readiness Assessment}

So how do weather-readiness assessments help mitigate these problems? Weather-readiness assessment is a formal method which makes use of analytical tools to critically assess a utility's preparation to tackle the impact of weather volatility on its operations. This includes a thorough study of the current 'state-of-the-system' with respect to weather volatility and identifies specific actions to ensure operational resilience during severe weather. Using the weather-readiness assessment framework helps utilities identify the overall influence of weather, gaps in the current health of their systems with respect to weather resilience, and measure how weather variables impact their business goals of providing reliable power, maintaining service levels and reducing operational costs. There are several benefits to utilities adopting weather-readiness assessments. At an operational level, being weather-ready improves process efficiency and enhances service quality to the end-users and eventually improves customer satisfaction. At the larger industry level, electric utilities that undergo this assessment pioneer best practices in the sector and can utilize the outcomes of the assessment as a competitive advantage, by enhancing performance and cutting down costs associated with being weather-resilient. All utilities embarking on such an assessment send a positive message on how prepared the electricity sector is to handle the increasing trend of weather volatility. Finally, being weather-ready means that utilities are not 'reacting' to every weather event but instead have clarity of how weather impacts each of their functions and proactively figure out what they need to do to keep their operations resilient during storms and/or other severe weather events.

\section{How Does the Industry Benefit from Being Better 'Weather-Ready'?}

The severe weather volatility seen in different parts of the world in the recent past have forced utilities to make unplanned expenses in restoration and recovery efforts, especially during superstorms. These ad hoc expenses, especially when they are a significant investment during a multi-storm year, make their financials look less than optimal. Unplanned expenses can 
also divert funds from future investments leading to ageing infrastructure that has been denied the appropriate upgrades required for being weatherresilient, making it more vulnerable in the future, thus fuelling a vicious circle. So utilities have a good reason to design a weather-readiness assessment framework that will make them better prepared and able to respond effectively to the next severe weather event which will test their service reliability.

\section{Defining Outcomes of Weather-Readiness Assessment}

Weather-readiness assessments can be done in any part of the electric utilities value chain - whether it is electricity generation, transmission and distribution or retail services-but the assessment can be successful only if it is linked to business outcomes in the corresponding business. And for companies that operate in more than one part of this value chain, the assessments too can be modified to reflect a multitude of business outcomes (see Fig. 4.4). For example, at an enterprise level, it is a high-level goal to optimize the cost of emergency operations. At a 'generation' utility level, outcomes are linked to incorporating distributed generation (mostly renewables) effectively in the overall generation portfolio. On the transmission and distribution side, business outcomes are linked to bringing

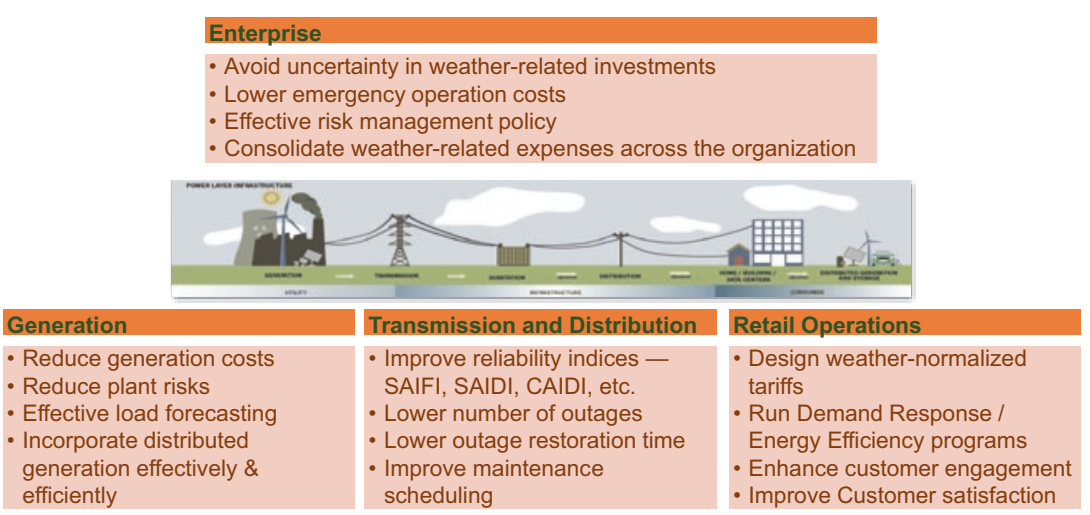

Fig. 4.4 Business outcomes driving weather-readiness assessment. Electricity Value Chain Graphic adapted from 'Utility Analytics Market \& Energy Analytics Market Global Advancements, Business Models, Worldwide Market Forecasts and Analysis (2013-2018)' 
down the duration of outages during a storm, and finally, in retail it is linked to improved customer satisfaction by improving communication during storms and delivering superior service.

Once business outcomes are identified, they are converted into realizable operational outcomes. A risk management policy document that includes a section on ensuring adequate storm preparedness and mandating that all departments include weather readiness as part of their annual operational due diligence is one manifestation of an operational outcome. Other manifestations could support a heightened level of current situational awareness by using equipment and decision-support applications to get a real-time 'state-of-the-system' view of utilities' assets integrating climate and weather information. Sometimes it could also be linked to a future objective, so when there is a plan to install a new asset, a weatherreadiness assessment could become an integral part of the due diligence of the location. That is the reason operational outcomes have to be backed by measurable quantitative metrics. These are metrics which will have to make economic sense for the utility, so an operational outcome focusing on improving service reliability will have to go through a cost-benefit analysis of reduction in the number/duration of weather-related outages juxtaposed with the cost to successfully achieve these metrics. It is also important that these metrics have the buy-in from various functions of the company as well as supporting comparison studies industry-wide. So in the above example, being reliant upon industry standardized service reliability metrics such as SAIDI and System Average Interruption Frequency Index (SAIFI) will add much more credibility to the assessment outcomes.

Weather readiness will have to be performed keeping expenses in check, so it is important that utilities do not embark on theoretical assessment studies that are a disproportionate sink of time and effort if they do not contribute effectively to making a good business case. And to make a business case, the true cost of the assessment must be taken into account, some of which could be indirect as well. An example of a direct cost could be the expense of integrating weather-based decision-support features into an existing utility distribution automation application, whereas an example of an indirect cost could be the opportunity cost of setting aside an exorbitant annual 'reserve fund' for multiple severe weather events and thereby denying much-needed system hardening investments within the utility's asset network. 


\section{Preparation for an Effective Weather-Readiness Assessment Framework} Once the weather-readiness assessment activity has been tested for its economic feasibility, the next step is to ensure that the data used for such assessments are robust. Assessing weather readiness as part of siting a new infrastructure within the service territory will require multiyear normalized climate data to understand weather patterns in a specific geographical location, while a situational awareness application focused on supporting severe weather events might need highly granular sub-second weather records such as lightning data that is updated in real time. Preparing the right kind of weather data also offers opportunities to coordinate and optimize requirements across multiple functions in the organization. So the power generation side of a bundled utility might be archiving weather data for forecasting load for several years and most of that archived weather data for multiple locations can also be used on the operational side to support machine learning algorithms to understand how specific weather variables such as temperatures and wind speeds play out in that location during extreme weather conditions.

\section{Interesting Applications at the Intersection of Energy and Meteorology}

Having a robust data layer allows utilities to design weather-based decision support across the utility. And decision-support applications can be delivered with varying levels of sophistication. At the simplest level, it could be a simple report which elaborates weather variables observed at any given location at a given time in the past week or month or for any given severe weather event. A post-mortem analysis of a heat wave or cold wave usually just requires a simple time-series of weather variables (usually of just temperatures) to understand the times when the utility demand was most stressed.

This might not be the case in an application which is a sophisticated decision-support application predicting asset damage from an incoming storm event. The same weather data in the earlier application is now regressed with data regarding location and performance of utility assets during similar weather conditions in the past. This 'historical patterns' data is then combined with non-weather variables such as vegetation and land use data to identify how a utility service territory will hold up during forecasted stormy weather based on historical behaviour. This allows utilities to predict and simulate severe weather's impact on their facilities and 
predict service interruptions to their end-users. The same data can also drive automated applications which can optimize system decisions such as reconfiguring power through alternative transmission or distribution network paths based on availability of network bandwidth which is not impacted by an incoming storm. This ensures that the degree to which service level performance is compromised is kept to a minimum and customer satisfaction levels can be maintained by constant communication and prompt restoration.

At a retail service level, products such as smart thermostats and services and smart utility bills normalized using weather data utilize hyperlocal weather data at a location to deliver unique decisions for energy management of residential, commercial and industrial premises. For a residential customer, it aids lifestyle decisions for the overall comfort while for a commercial customer it supports energy-efficiency initiatives. Of course, as the electrical grid gets smarter, the possibilities of how weather data can be applied using electricity supply and demand data at multiple nodes in the power grid can be endless. Figure 4.5 shows examples of current and future electric utility applications (across enterprise, grid and consumer applications) which can be enhanced by weatherbased decision support.

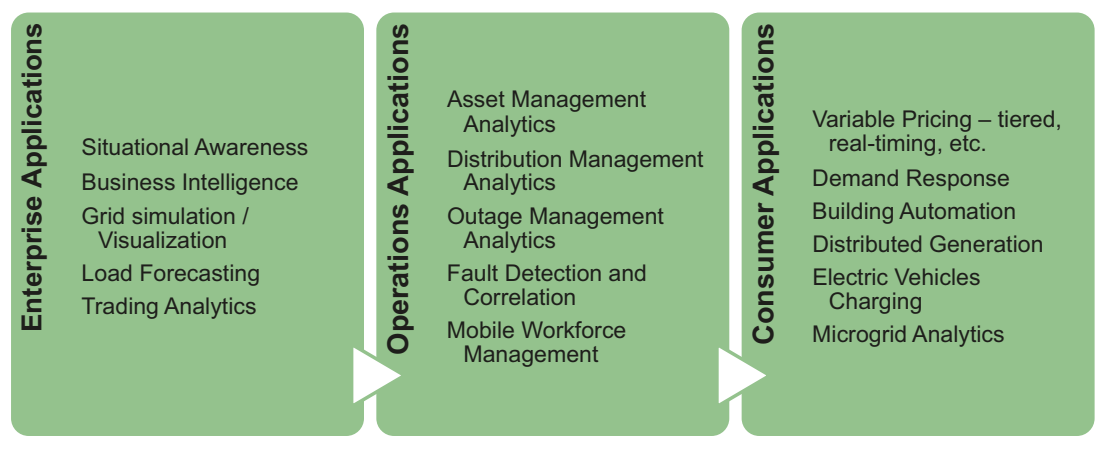

Fig. 4.5 Electric power sector applications enhanced by weather-based decision support. Graphic Adapted from 'Utility Analytics Market \& Energy Analytics Market (Solar Analytics, Oil o Gas Analytics, Water analytics, Waste analytics): Global Advancements, Business Models, Worldwide Market Forecasts and Analysis (2013-2018)' 
Even though weather-readiness assessments can follow a generic framework, they have to be customized in a specific way for any utility to take advantage. Also, it is important that organizations take a larger cross-functional system view of the assessment and create a template for their overall readiness rather than individual departments producing separate silos of assessments without appreciating the synergies and conflicts within the organization. Millions of dollars are being spent worldwide on managing the risks associated with weather (Lazo et al. 2011) and this assessment tool should help utilities decide whether it is spent on the highest priority ones and aligned with the larger business outcomes.

\section{Next Steps in the Dialogue Between Energy and Meteorology}

It is obvious that weather and climate have become more and more important for the energy sector as a) climate change demands an urgent need for adaptation of energy systems on the long term and b) the necessary, increasing share of variable renewables generation-mainly wind and solar-requires quick and significant improvements in weather forecasts, now, on short-term lead times.

As demonstrated in the other chapters in this book, and in many other publications (e.g. Troccoli et al. 2014), the meteorology community has, in the last decade or so, improved knowledge on many energy-relevant aspects; new forecasting tools, methods and products have been made available, and the research and development agenda promises significant new progress in the coming years. But scientific and technical progress alone is not enough to improve energy systems. Indeed, two key additional ingredients are necessary to improve weather readiness (Lazo 2007; Rogers et al. 2007; Dubus 2014):

1. Improved communication between providers and users of the weather and climate information, and

2. Improved decision-making processes.

These two critical aspects will be investigated further in the following chapters (Chaps. 5, 6, 7, 8, 9, 10, 11 and 12) and summarized in the concluding chapter (Chap. 13). 
Acknowledgements The authors thank EDF colleagues, especially Marc Trottignon and Vera Silva, for providing material and feedback, and ICEM 2015 energy seminar lecturers: Christian Brose (EON), Mark Zagar (Vestas), Mathieu Anderhalt (EDF) and Marion Schroedter-Homscheidt (DLR).

\section{Appendix: Key Documentation on the Energy Sector}

Different organizations gather, analyse, organize and disseminate information about energy worldwide. We list here some of the most relevant ones, and provide the links to the latest releases of their key documents.

- The World Energy Council (http://www.worldenergy.org) provides several key publications:

- World Energy Focus http://worldenergyfocus.org/annual-2016/ http://worldenergyfocus.org/annual-2016/

- World Energy Resources http://www.worldenergy.org/publications/2016/world-energy-resources-2016/http://www.worldenergy.org/publications/2016/world-energy-resources-2016/

- Energy Trilemma Index http://www.worldenergy.org/ publications $/ 2016 / 2016$-energy-trilemma-index-benchmarkingthe-sustainability-of-national-energy-systems/http://www. worldenergy.org/publications/2016/2016-energy-trilemma-indexbenchmarking-the-sustainability-of-national-energy-systems/

Many other reports are available on the publications page of the website (perspectives, scenarios ...). A nice 4 minute movie summarizes the current status and main challenges in achieving the Energy Trilemma.

- The International Energy Agency publishes reference documents every year in November

- the World Energy Outlook (http://www.iea.org/newsroom/ news/2016/november/world-energy-outlook-2016.html). A movie is also available with the 2016 edition. The IEA also produces special reports

- World Energy Statistics http://www.iea.org/bookshop/723World_Energy_Statistics_20l6http://www.iea.org/ bookshop/723-World_Energy_Statistics_2016 
Note that IEA documents have an associated cost, but executive summaries can be downloaded freely.

- The Renewable Energy Policy Network for the 21st Century (REN21) publishes a Yearly Renewables Global Status Report http://www.ren21.net/status-of-renewables/global-status-report/

\section{Notes}

1. http://www.se4all.org/.

2. https://www.worldenergy.org/.

3. https://www.iea.org/.

4. http://www.ren21.net/.

5. It has to be noted that available statistics are generally delayed by $1-2$ years, the necessary time for organizations to gather, clean and analyse data from multiple sources.

6. https://www.hydropower.org/.

7. https://www.esmap.org/.

\section{REFERENCES}

Anderhalt, M. (2015). Power plants and climate change. How to optimize environmental performances of power plants' cooling systems? ICEM 2015 Energy Seminar, Boulder, Co, USA, June 2015. Retrieved from http://www.wemcouncil.org/wp/wp-content/uploads/2015/07/1415_MathieuAnderhalt. pdf; http://www.wemcouncil.org/wp/wp-content/uploads/2015/07/1415_ MathieuAnderhalt.pdf

Baggini, A. (2008). Handbook of power quality. Chichester: Wiley, 642pp. ISBN: 978-0-470-06561-7.

Dubus, L. (2014). Weather and climate and the power sector: Needs, recent developments and challenges. In A. Troccoli, L. Dubus, \& S. E. Haupt (Ed.), Weather matters for energy (XVII, 528 p.). New York: Springer. ISBN 978-1-4614-9220-7.

Elias, T., Ramon, D., Dubus, L., Bourdil, C., Cuevas-Agullo, E., Zaidouni, T., et al. (2015). Aerosols attenuating the solar radiation collected by Solar Tower Plants: The horizontal pathway at surface level. AIP Conference Proceedings, 1734(1). https://doi.org/10.1063/1.4949236.

Elias, T., Ramon, D., Garnero, M. A., Dubus, L., \& Bourdil, C. (2016). Solar energy incident at the receiver of the solar tower plant derived from remote sensing. Part 1: Computation of both DNI and slant path transmittance. Poster presented at SolarPaces, Abu-Dabi. 10.13140/RG.2.2.19957.37609. 
Francis, J., Vavrus, S., \& Tang, Q. (2014). Rapid arctic warming and mid-latitude weather patterns: Are they connected? State of the Climate in 2013. Retrieved from http://journals.ametsoc.org/doi/pdf/10.1175/2014BAMSStateofthe Climate.1

Garnero, M. A., Bourdil, C., Dubus, L., Elias, T., \& Ramon, D.. (2016). Solar energy incident at the receiver of the solar tower plant derived from remote sensing. Part 2: Impact of the variability of attenuation on plant energy performances. SolarPaces, Abu-Dabi.

HRW. (2014). Future climate for Africa - scoping papers: Examining the utility and use of long-term climate information for hydropower schemes in sub-Saharan Africa. Wallingford, UK: HR Wallingford, 41 pp. Retrieved from https:// assets.publishing.service.gov.uk/media/57a089b7e5274a27b2000217/ hydropower.pdf

IDC. (2013). Business strategy: Facing down extreme weather. IDC Energy Insights, \#EI242104

IEA. (2016a). Key world energy statistics 2016. (C) OECD/IEA, IEA Publishing. Licence: www.iea.org/t\&c. Retrieved from https://www.iea.org/publications/freepublications/publication/KeyWorld2016.pdf

IEA. (2016b). World energy outlook 2016. (c) OECD/IEA, IEA Publishing. Licence: www.iea.org/t\&c. Retrieved from http://www.worldenergyoutlook. org/publications/weo-2016/

IHA. (2016). Hydropower status report, 2016. International Hydropower Association. Retrieved from https://www.hydropower.org/2016-hydropowerstatus-report

IPCC. (2013). Climate change 2013: The physical science basis. Contribution of working group I to the fifth assessment report of the intergovernmental panel on climate change [Stocker, T. F., Qin, D., Plattner, G.-K., Tignor, M., Allen, S. K., Boschung, J., Nauels, A., Xia, Y., Bex, V., \& Midgley, P. M. (eds.)]. Cambridge, UK; New York: Cambridge University Press, 1535 pp. https:// doi.org/10.1017/CBO9781107415324. Retrieved from https://www. hydropower.org/2016-hydropower-status-report

Jackson, R. B., Canadell, J. G., Le Quéré, C., Andrew, R. M., Korsbakken, J. I., Peters, G. P., et al. (2015). Reaching peak emissions. Nature Climate Change, 6, 7-10. https://doi.org/10.1038/nclimate2892.

LaCommare, K. H., \& Eto, J. (2006). Cost of power interruptions to electricity consumers in the United States (U.S.). Lawrence Berkeley National Laboratory, LBNL-58164. Retrieved from https://emp.lbl.gov/sites/all/files/reportlbnl-58164.pdf

Lazo, J. K. (2007). Economics of weather impacts and weather forecasts. In Rose, T. (Ed.), Elements for life, a WMO publication for the Madrid Conference. ISBN: 92-63-11021-2. 
Lazo, J. K., Lawson, M., Larsen, P. H., \& Waldman, D. M. (2011). U.S. economic sensitivity to weather variability. $B A M S, 709-720$. https://doi.org/10.1175/ 2011BAMS2928.1.

REN21. (2016). Renewables 2016 global status report. Paris: REN21 Secretariat. ISBN: 978-3-9818107-0-7.

Rogers, D., Clark, S., Connor, S. J., Dexter, P., Dubus, L., Guddal, J., et al. (2007). Deriving societal and economic benefits from meteorological and hydrological services. WMO Bulletin, 56(1), 15-22.

SE4ALL. (2014). Sustainable energy for all 2014 annual report. United Nations. Retrieved from http://www.se4all.org/sites/default/files/l/2015/05/ SE4ALL_2014_annual_report_final.pdf

Troccoli, A., Dubus, L., \& Haupt, S. E., (eds.). (2014). Weather matters for energy. New York: Springer. ISBN: 978-1-4614-9220-7 (Print) 978-1-4614-9221-4 (Online).

WEC. (2016a). World energy perspectives 2016: The road to resilience - managing the risks of the energy-water-food nexus. World Energy Council Report. ISBN: 978-0-946121-47-2.

WEC. (2016b). World energy resources, 2016. World Energy Council Report. ISBN: 978-0-946121-58-8.

WEC. (2016c). World energy perspectives 2016. Executive Summary. ISBN: 978-0-946121-51-9.

WEC. (2016d). World energy trilemma 2016. Executive Summary. ISBN: 978-0-946121-49-6.

WEC. (2016e). World energy scenarios 2016. The grand transition summary report. ISBN: 978-0-946121-57-1.

Open Access This chapter is distributed under the terms of the Creative Commons Attribution 4.0 International License (http://creativecommons.org/licenses/ by $/ 4.0 /$ ), which permits use, duplication, adaptation, distribution and reproduction in any medium or format, as long as you give appropriate credit to the original author(s) and the source, a link is provided to the Creative Commons license and any changes made are indicated.

The images or other third party material in this chapter are included in the work's Creative Commons license, unless indicated otherwise in the credit line; if such material is not included in the work's Creative Commons license and the respective action is not permitted by statutory regulation, users will need to obtain permission from the license holder to duplicate, adapt or reproduce the material.

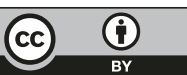

